\title{
More Than A Recruitment Task In German Hospitals: Effects Around Cultural Diversity Of Physicians' Impatriation
}

Andreas J. Reuschl, University of Bayreuth, Germany

Ricarda B. Bouncken, University of Bayreuth, Germany

\begin{abstract}
Hospitals in industrialized countries increasingly recruit foreign physicians and thus have to work with a diverse workforce that exerts challenges. On the basis of social identity theory and the jobresources-demands model, the authors discuss effects on job performance, the intention to leave, and develop a set of propositions.
\end{abstract}

Keywords: Diversity; Migration; Hospital; Performance; Intention To Leave

\section{INTRODUCTION}

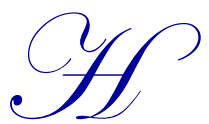

ospitals in industrialized countries have a demand for physicians that cannot be covered with the domestic workforce; thus, hospitals try to attract physicians from abroad. Physicians from less industrialized countries are willing to leave their home countries for higher salaries or training abroad. For example, over $60 \%$ of Polish and Pakistani medical students consider working abroad after their graduation (Krajewski-Siuda et al., 2012; Syed, Khimani, Andrades, Ali, \& Paul, 2008). Studies on the migration of physicians distinguish between push and pull factors of migration (Hagopian et al., 2005; Krajewski-Siuda et al., 2012; Mullan, 2006). Pull factors center on the marketing of hospitals and their offerings in terms of salaries, training, and working conditions. For example, the main destination of health workers is North America (Cooper, 2005; Dacuycuy, 2008; Grignon, Owusu, \& Sweetman, 2013). Push factors center on opportunities to escape from poorer living and working conditions (Nair \& Webster, 2012). Specifically, high rates of HIV infection in the population and the risks this poses for health care workers particularly motivate physicians in certain African regions to leave their home countries (Kirby \& Siplon, 2012).

The migration of physicians provides great potential for both hospitals and physicians, simultaneously exposing great challenges that stem from different educational backgrounds, language barriers, and cultural diversity. The latter is the kernel of this paper. Cultural diversity is associated with the confrontation of different value and behavioral models that can enrich the resource base and stimulate new ideas, as proposed by the information/decision-making theory (Williams \& O'Reilly, 1998), but still can breed reduced effectiveness, misunderstanding, failure, conflict, and barriers, as proposed by the categorization and discrimination principles of the social identity theory (Tajfel \& Turner, 1986).

Research shows that greater diversity in terms of different nationalities reduces communication effectiveness in an organization (Davidhizar \& Dowd, 1999; Gudykunst \& Nishida, 2001). Particularly, severe errors in the delivery of treatment occur when physicians only partially understand patients' needs and problems (Wilson, Chen, Grumbach, Wang, \& Fernandez, 2005). Different educational backgrounds and values will induce the need for debates and stimulate conflicts. Conflicts can arise through group processes, discrimination and eventually social exclusion (Burkard, Boticki, \& Madson, 2002; Jehn, Northcraft, \& Neale, 1999; King, Dawson, Kravitz, \& Gulick, 2012; Pelled, Eisenhardt, \& Xin, 1999). Finally, the reduced communication effectiveness, in combination with an increasing rate of conflicts, might decrease organizational performance. Studies find a negative relation between diversity and performance (Gonzalez \& DeNisi, 2009; Richard, 2000; Weech-Maldonado, Al- 
Amin, Nishimi, \& Salam, 2011) and Zhou and Shi (2011) provide a good overview over the consequences of cultural diversity.

International HR recruitment and the integration of physicians and nurses is highly important for hospitals. Yet, despite this great importance, research so far has neglected effects of the migration of physicians.

This study aims to discuss this important topic based on the social identity theory in combination with the job-demands-resources model. To research the consequences of diversity the authors focus on German hospitals and on the point of view of migrant physicians. In the discussion of the relevant literature the authors will develop a set of propositions.

\section{DEVELOPMENT OF THE PROPOSITIONS}

\section{Theoretic Background}

Social Identity Theory

Social identity theory (SIT) provides a theoretical framework for the understanding of diversity in organizations (Hentschel, Shemla, Wegge, \& Kearney, 2013; Williams \& O'Reilly, 1998). The SIT proposes that individuals sort themselves and others into social categories along individual preferences (Ashforth \& Mael, 1989). The theory is grounded in the longing of individuals for orientation in a society, classifying themselves in relation to others. Following Tajfel and Turner (1986), individuals strive for a positive self-awareness which can be generated through the membership in a social group. Hence, a positive social identity is defined by favorable in- and out-group comparisons, whereas a negatively valued identity can lead to a redefinition or the transition to another group. Switching social groups is predetermined by the individual value- and belief-system. The concept of social mobility offers individuals the ability to change their social group through their own efforts; social change depicts societies with salient marks which enable a fixed stratification. The social change mindset therefore describes the negligence of individual characteristics in favor of salient group attributes.

Consequently, the affiliation with a social group is not fixed. A person is able to change his perceived group affiliation and vice versa. The process of identification takes place on a cognitive level and has not to be connected with real facts or behaviors (Ashforth \& Mael, 1989). As Hogg and Turner (1985) point out, group formation and social identification can be generated through the application of random categorization attributes. Of course, a strong social identification is reached according to the principle of reaching a high self-esteem through group membership (Tajfel \& Turner, 1986). If the group affiliation is not positively valued, an alignment of the value- and belief-mindset to social change enables a strong social identity regardless (Hogg \& Turner, 1985).

The critical forces for identification develop from perceived dissimilarities or perceived similarities if an explicit categorization is not available (Hogg \& Turner, 1985). It is to be stressed that the crucial word here is "perceived" and that identification, as well as categorization, is mainly based on perception.

Following the SIT, the basis for the diversity is an individual's recognition and subjective processing of differences to others. Even if objective differences exist, they can been overseen. For example, a dominant amount of important shared attributes, like "being a physician", can outweigh objective diversity (Hentschel et al., 2013). Subjective diversity then might not be existent or discovered. Vice versa, typical diversity-related issues might appear in a homogenous group because of a specific psychological category; for example, "football club fan". Consequently, the authors argue that subjective and perceived diversity is the main trigger of social identity building and faultiness causing important effects in organizations (Hobman, Bordia, \& Gallois, 2004).

Following the work of Hobman, Bordia, and Gallois (2004), the authors integrate visible (age, gender, ethnicity) work value (work standards) and informational dissimilarity (professional background, tenure, experience) to overall dissimilarity. This allows the inclusion of surface-level and deep-level diversity. 


\section{Job Demands-Resources Model}

Whereas the SIT facilitates the understanding of diversity, the Job Demands-Resources Model (JD-R) can explain cause-effect relations of diversity. The JD-R is rooted in the job strain and burnout research. From the viewpoint of the JD-R model, individuals - in this paper, physicians - compare available resources with the demands of their jobs (Demerouti, Bakker, Nachreiner, \& Schaufeli, 2001). Hereby, resources comprise all organizational factors that help to fulfill a task, reduce the demands of a task (physical and psychological costs), and enhance individual development; for example, feedback, rewards, job security, work autonomy, or training. In contrast, job demands represent all physical or psychological, organizational or job-related characteristics that increase the demands of a task, e.g. physical workload, time pressure, shift work, and physical environment (Demerouti et al., 2001). The impacts proposed by the JD-R model arise from the dual process of high job demands causing exhaustion (energetic process) and low levels of available resources leading to disengagement motivational process (A. Bakker, Demerouti, \& Schaufeli, 2003; Demerouti et al., 2001; Schaufeli \& Bakker, 2004).

Demands and resources interact, as high resource levels balance high demands or low job demands require fewer resources (A. B. Bakker \& Demerouti, 2007). Eventually it is important to note that different types of demands require different types of resources to reduce negative consequences (A. B. Bakker \& Demerouti, 2007). Moreover, the interaction between resources and demands was investigated by Van Vegchel, De Jonge, and Landsbergis (2005). The authors conclude that a multiplicative interaction term is most suitable to describe the relation of resources, demands, and outcomes.

The JD-R model predicts organizational consequences for a disproportionate ratio between demands and resources. Schaufeli and Bakker (2004) conclude that negative consequences of the JD-R model are health problems, burnout, or the intention to leave. The authors acknowledge that increasing resources, such as participative management or social support, counteract these effects. Evidence on the effects of JD-R on turnover intentions via organizational commitment is given by Bakker, Demerouti and Schaufeli (2003). Karasek (1979) shows that decreasing demand levels increase job or even life satisfaction.

Integration of the SIT into the JD-R model supports the development of a new understanding of the effects of diversity. As a steady social identity includes group affiliation, raised self-esteem and social support through social networks, it can be theorized as a job resource (Hobfoll, Freedy, Lane, \& Geller, 1990; Van Yperen \& Hagedoorn, 2003). On the contrary, an unstable social identity describes mollified self-esteem and missing social support due to e.g. unclear group affiliation. Resulting interpersonal misunderstandings or conflicts could be treated as social job demands (Ilies, Johnson, Judge, \& Keeney, 2011).

Therefore, the SIT is able to give an indication on job demands, as well as job resources, and proves perceived dissimilarity - respectively, perceived diversity - to be an important antecedent of organizational outcomes. The strength of the effects is assumed to be on the individual perceived salience of the regarded differentiator.

\section{Work Conditions And Diversity Of Physicians}

Migration of physicians usually concerns movements from low income to high income countries and from rural to urban areas. This process brings a knowledge transfer and cultural diversity from the health professionals' workforce (Docquiera \& Rapoportb, 2006; Dodani \& LaPorte, 2005; Eyal \& Hurst, 2008; Nair \& Webster, 2012; Sherr et al., 2012).

Physicians have specific tasks and roles in hospitals and often work in groups which carry out tasks that are largely standardized but require high specialization and great interdependence. Dependent on the patient's disease, tasks differ in terms of task analyzability and variability. Standardized work means that the work content and necessary procedures occur in a large number of cases in which physicians apply their knowledge and skills.

Standardized tasks require a common learning and skill base across organizational members, including impatriated physicians. If these commonalities do not exist, problems and mistakes are most likely to occur and 
further training or communication and coordination will be necessary. A high specialization states the specific actions and skills brought into anamnesis and treatment across different roles of physicians. Largely, they require the coordination and integration of different work roles which must be known by professional education and/or further practice-orientated training in hospitals. If roles of specialized work are not clear, they will cause great coordination and training effort and highly likely cause misunderstandings.

Task interdependence reveals connectivity between tasks. Thompson and Bates (1957) assume that tasks are highly sequentially interdependent when one task requires the completion of another. If tasks continuously require multiple editors, they are reciprocally interdependent (Thompson, 1967) Task interdependence includes influences of liaison with other individuals. It then states requirements of communication, coordination, and teamwork. Naturally, differences of knowledge, behavior and values become influential under high task interdependence. Highly interdependent tasks require high coordination efforts from personnel when they try to adjust their work procedures. Interdependence also needs coordination often in the form of discretionary power requirements to coordinate their interconnected actions (Perrow, 1967). Interdependence strongly imposes communication and cooperation skills upon personnel (Van De Ven, Delbecq, \& Koenig, 1976). Objective and perceived diversity strongly determine problems under high tasks interdependence.

A task's analyzability is related to the problem-solving processes undertaken when exceptions occur. Greater task analyzability indicates greater difficulty (Van De Ven et al., 1976). Variability of tasks is an indicator for the amount of exceptions occurring during task fulfillment (Perrow, 1967); it denotes higher task complexity (Pugh, 1973) which, in turn, often requires greater interaction between personnel. Due to the nature of work in hospitals, particularly the high tasks interdependence, physicians will experience high levels of diversity if differences are sufficiently salient.

Immigrants tend to be perceived as dissimilar from employees born in the host country; therefore, an initial salient dissimilarity can be assumed (J. W. Berry, 2001). The SIT helps to understand the consequences of physician migration and the resulting increase in workforce diversity. Judging from this theory, newly migrated physicians strongly perceive differences and then will mentally exaggerate the dissimilarities between themselves and other employees in their new employers' organization. A high likelihood for this behavior can be derived from obviously different categories like nationality, culture, religion or, for example, language.

\section{Effects On Job Performance}

\section{Job Performance}

Job satisfaction describes an organizational member's satisfaction with the goals of his job, the job content, working conditions, and career opportunities. In the light of the Job-Demands-Resources Model, job satisfaction depends upon incentives, contributions, and perceived integration and equality within job roles in relation to the workload. The cultural distance literature (Shenkar, 2001) argues that the fit between organizations or individuals decreases as the measured cultural characteristics increasingly deviate. Suanet and Van de Vijver (2009) investigated the impact of cultural distance for exchange students in Russia and found that a high perceived cultural distance leads to less psychological and sociocultural adjustment (Suanet \& Van de Vijver, 2009). Following Kirchmeyer (1993), the minority status of group members also leads to a lower organizational contribution. Migrated physicians are likely to perceive a minority status. Other studies demonstrated that the actual or perceived dissimilarities influences the performance of a group or an organization through a changing group development (Shaw \& Barrett-Power, 1998), or changing conflict patterns (Jehn, Chadwick, \& Thatcher, 1993; Pelled et al., 1999). Impatriated physicians accomplish the same tasks as their German co-physicians (Gramm \& Schnell, 2001) and are implicitly requested to show equal motivation and performance, yet they face serious obstacles in language barriers, social disintegration, and out-group existence. The resulting imbalance reduces job satisfaction of impatriate physicians. Combining the discussed effects of diversity with SIT, the authors argue that a high perceived dissimilarity has a negative effect on performance.

Proposition 1a: The perceived dissimilarity of impatriated physicians is negatively related to their job performance. 


\section{Intention To Leave}

Performance and effectiveness in hospitals depends on coordinated and seamless work of physicians and their commitment. The highly sequential and reciprocal interdependence of tasks in hospitals requires coordination, mutual adjustment, interpersonal understanding, and joint experiences. Lower levels of those will reduce effectiveness. Ongoing problems in the coordination and experience of diversity, or even discrimination, will reduce the motivation and commitment of impatriated physicians. This can increase their intent to leave or induce the termination of the work contract. Particularly due to the high interdependence, hospitals will try to build up a longterm workforce and try to avoid turnover. An important parameter and widely accepted predictor for voluntary turnover is organizational commitment (Allen \& Meyer, 1990; McKay et al., 2007), which describes the strength of an employee's relationship with an organization (Mowday, Steers, \& Porter, 1979).

The SIT, as it describes the dis-/similarity between individuals and their belonging to a group, provides an important factor for the relationship strength between migrated physicians and German hospitals - respectively, the impatriated physician's organizational commitment. Bozionelos (2009) found that foreign nurses in Saudi-Arabia had a higher intention to leave the organization than those from Saudi-Arabia (Bozionelos, 2009). The authors argue that the perceived dissimilarity is an underlying reason for the intention to leave an organization (Mor Barak, Nissly, \& Levin, 2001). Employees who are not able to identify themselves with their organization and regard themselves as part of one social category are more likely to have the intention to leave an organization.

Proposition 1b: The perceived dissimilarity of foreign physicians is positively related to their intention to leave.

Moreover, a mediating role is assigned to the intention to leave in the negative relation between perceived dissimilarity and job performance. As the SIT showed, high levels of dissimilarity create a feeling of not belonging to a group - respectively, organization. If physicians lack this feeling of belonging or identification, they are likely to look for new job opportunities. This, in turn, reduces the effort physicians are willing to make.

Proposition 2: The intention to leave of foreign physicians mediates the negative relation between perceived dissimilarity and job performance.

Still, there will be physicians who have internally quit without visible reductions of performance in terms of quality triggered by the commitment to the fate and health of patients.

\section{Moderating Role Of Integration Instruments}

Based on the SIT, the authors propose that a high perceived dissimilarity decreases job performance and increases the intention to leave of foreign physicians in German hospitals. While physicians might perceive a high dissimilarity between themselves and other organizational members, a psychological similarity, or a similar psychological social category could outweigh the effects of the social categorization due to simple stereotyping ( $\mathrm{J}$. W. Berry, 2001). Hence, the relationship between perceived dissimilarity and job performance and, accordingly, intention to leave is moderated by the degree of social and professional integration.

The concept of integration is based on the research on social support which is primarily focused on the relation between social support, stress, and health (Cobb, 1976; Cohen \& Wills, 1985). Through the expansion of the concept on social network theory and group cohesion, it was used by other disciplines to explain organizational effects (Berkman, Glass, Brissette, \& Seeman, 2000; O'Reilly III, Caldwell, \& Barnett, 1989). Following House, Umberson, and Landis (1988), the concepts of social integration, social support, and social networks are regarded as equal and interchangeable and use the label integration for the idea.

Integration is a complex construct describing the availability and quality of personal relationships, comprising emotional (caring, trust), instrumental (tangible support, e.g. money), informational (e.g. information for problem-solving), and appraisal (information for self-evaluation) components (Leavy, 1983). O’Reilly, Caldwell, and Barnett conclude "s[S]ocial integration [, therefore, ] can best be thought of as a multifaceted phenomenon that reflects attraction to the group, satisfaction with other members of the group, and social interaction among group 
members" (O'Reilly III et al. (1989), 22). Therefore, integration comprises aspects of experienced support and a feeling of belonging to a social network.

The affection-component is especially important for research on the migration of physicians. Studies already exposed the moderating influence of integration on stress-related issues or, for example, the intention to leave (Lim, 1996; O'Reilly III et al., 1989). High levels of integration offer individuals a feeling of being loved, cared about, and - above all - belonging to group with mutual responsibilities (Cobb, 1976; Cohen \& McKay, 1984). As stated, the SIT suggests that migrated physicians obviously will feel dissimilar and, consequently, decreased performance, thus increased intention to leave can be expected.

Dissimilarities between individuals impede integration (Jackson et al., 1991; Lincoln \& Jon, 1979; Milliken \& Martins, 1996; O'Reilly III et al., 1989; Tsui \& O'Reilly III, 1989). However, high levels of integration provide the opportunity to change these effects, as the perceived integration could be able to outweigh the effects of perceived dissimilarity. The possibility for this constellation is given through the psychological group identification and formation; for example, based on the attribute "being a physician".

Following Lim (1996), the authors distinguish between work-related integration (professional integration) and non-work-related integration (social integration). Whereas Lim (1996) pursues a deeper understanding of factors influencing stress, a distinction between social and professional integration is necessary due to the unique situation of migrants. A freshly migrated physician lacks social, as well as professional, ties and networks in his host country and has to build up both from scratch. Exhibiting surface-level differences like language or e.g. appearance and having deep-level differences like values or e.g. religion, an immigrant might suffer from social, economic or cultural exclusion (Cvetkovic, 2009). The reception of immigrants in a host country can be categorized as disadvantaged, neutral, or advantaged (Iredale, 2001; Portes \& Böröcz, 1989). Hence, an immigrant can experience a "closed" society or even discrimination, a treatment characterized by neutrality and indifference, or an encouraging and supporting surrounding. Immigrated physicians can encounter these reception categories in a social and a professional environment. The reception in the host country, thus, might be decisive for the perceived dissimilarity.

Empirical evidence marks professional integration as the more important influence, but the research setting of most studies deviates from the presented argumentation. In contrast to Lim (1996) or LaRocco, House, and French (1980), the authors propose that social and professional integration are important moderators of the relation between perceived dissimilarity and job performance, as well as the intention to leave. Integration will, in spite of high dissimilarity, weaken the negative effects of high perceived dissimilarity on performance and the intention to leave.

Proposition 3a: The negative/positive relationship between foreign physicians' perceived dissimilarity and job performance/intention to leave is moderated by the social integration; the negative/positive effects of perceived dissimilarity will be weaker/stronger when foreign physicians are socially integrated.

Proposition 3b: The negative/positive relationship between foreign physicians' perceived dissimilarity and job performance/intention to leave is moderated by the professional integration; the negative/positive effects of perceived dissimilarity will be weaker/stronger when foreign physicians are professionally integrated.

Eventually, immigrants are expected to have the inherent longing for social, as well as professional, integration. Consequently, high levels of social integration, in combination with high levels of professional integration, are expected to achieve the highest positive influence on the proposed relations between perceived dissimilarity and job performance and the intention to leave.

Proposition 3c: The negative relationship between foreign physicians' perceived dissimilarity and job performance/intention to leave is moderated by the interaction of social and professional integration; the negative/positive effects of perceived dissimilarity will be weaker/stronger when foreign physicians are socially, as well as professionally, integrated. 


\section{CONCLUSION}

This study was motivated by the growing need of hospitals in industrialized countries to recruit and work with physicians from different national backgrounds. The diversity of nationalities is a breeding ground for misunderstanding and reduced job performance but also dissatisfaction of the foreign workers that even might trigger an intention to leave the hospital again. As hospitals differ in many respects from other industries (e.g. customers are at risk when receiving hospital services), there is still a lot of research to be done (L. L. Berry \& Bendapudi, 2007). This study provides important contributions to the current scientific literature on diversity and the hospital industry.

The authors developed a set of propositions embedded in the social identity theory (SIT). The SIT indicates categorization processes that emanate from an individual comparison of oneself with others, identifying similarities and differences. This has several implications. First, while an objective diversity of culture, skin-color, language, or e.g. gender suggests the formation of social categories, it is uncertain whether these attributes are salient features that start categorization processes. Second, categorization processes take place on several levels (Ashforth \& Mael, 1989). Taking a physician who migrated from Turkey to Germany, for example, illustrates this thought. The migrated physician will probably identify himself with social categories like "people that are male", "people from Turkey", "people who speak Turkish", or "people who are trained as physicians". Based on the chosen categorization criteria, research on gender diversity, cultural diversity, language diversity or professional diversity would be possible. All research endeavors would probably lead to differing results. Eventually, an organization might exhibit impartiality to diversity while the employees do not perceive diversity and vice versa. Therefore, the authors propose the necessity of more research on the differences between objective and subjective diversity.

Besides the consequences of diversity amongst employees, the investigation of diversity in the dyadic physician-patient relationship is of utmost importance. The authors assume that the role of perceived language abilities - respectively, communication skills - is a critical factor for building trust, reducing perceived risk and for accepting dependency (L. L. Berry \& Bendapudi, 2007; Collins, Clark, Petersen, \& Kressin, 2002; Doescher, Saver, Franks, \& Fiscella, 2000; Gordon, Street, Sharf, Kelly, \& Souchek, 2006). The quality of physician-patient relationships will eventually have an effect on the overall hospital quality and performance.

\section{ACKNOWLEDGEMENTS}

The authors conducted research in the project "Service4Health", funded by the German Federal Office for Research and Education (BMBF). This publication was funded by the German Research Foundation (DFG) and the University of Bayreuth in the funding programme Open Access Publishing

\section{AUTHOR INFORMATION}

Andreas J. Reuschl, M.Sc., is a research assistant at the chair of Strategic Management and Organization at the University of Bayreuth. After his bachelor studies, in cooperation with Siemens Healthcare (B.A. in International Management with Engineering), he completed the Master of Science in Management at the University of Bayreuth. In the course of the project "Service4Health", funded by the German Federal Office for Research and Education, he is conducting research in the German hospital sector, focusing on process, productivity, and diversity management. E-Mail: andreas.reuschl@uni-bayreuth.de (corresponding author)

Ricarda B. Bouncken, Professor, is the owner of chair of Strategic Management and Organization at the University of Bayreuth and can look back on many years of research and publication in the field of service management which comprises of topics like process systems, value chains, measurement of effectiveness, knowledge transfer within and between service providers as well as customer satisfaction. She initiated the project "Service4Health", funded by German Federal Office for Research and Education, and more than 130 publications have been submitted by her. EMail: bouncken@uni-bayreuth.de. 


\section{REFERENCES}

1. Allen, N. J. \& Meyer, J. P. (1990). The measurement and antecedents of affective, continuance and normative commitment to the organization. Journal of Occupational Psychology, 63(1), 1-18.

2. Ashforth, B. E. \& Mael, F. (1989). Social Identity Theory and the Organization. The Academy of Management Review, 14(1), 20-39.

3. Bakker, A., Demerouti, E., \& Schaufeli, W. (2003). Dual processes at work in a call centre: An application of the job demands-resources model. European Journal of Work and Organizational Psychology, 12(4), 393-417.

4. $\quad$ Bakker, A. B. \& Demerouti, E. (2007). The Job Demands-Resources model: state of the art. Journal of Managerial Psychology, 22(3), 309-328.

5. $\quad$ Berkman, L. F., Glass, T., Brissette, I., \& Seeman, T. E. (2000). From social integration to health: Durkheim in the new millennium. Social Science \& Medicine, 51(6), 843-857.

6. $\quad$ Berry, J. W. (2001). A Psychology of Immigration. Journal of Social Issues, 57(3), 615-631.

7. Berry, L. L. \& Bendapudi, N. (2007). Health Care: A Fertile Field for Service Research. Journal of Service Research, 10(2), 111-122.

8. Bozionelos, N. (2009). Expatriation outside the boundaries of the multinational corporation: A study with expatriate nurses in Saudi Arabia. [Article]. Human Resource Management, 48(1), 111-134.

9. Burkard, A. W., Boticki, M. A., \& Madson, M. B. (2002). Workplace Discrimination, Prejudice, and Diversity Measurement: A Review of Instrumentation. Journal of Career Assessment, 10(3), 343-361.

10. Cobb, S. (1976). Social support as a moderator of life stress. Psychosomatic Medicine, 38(5), 300-314.

11. Cohen, S. \& McKay, G. (1984). Social support, stress, and the buffering hypothesis: A theoretical analysis. Handbook of psychology and health, 4, 253-267.

12. Cohen, S. \& Wills, T. A. (1985). Stress, social support, and the buffering hypothesis. Psychological bulletin, 98(2), 310-357.

13. Collins, T. C., Clark, J. A., Petersen, L. A., \& Kressin, N. R. (2002). Racial Differences in How Patients Perceive Physician Communication regarding Cardiac Testing. Medical Care, 40(1), I27-I34.

14. Cooper, R. A. (2005). Physician Migration: A Challenge for America, a Challenge for the World. Journal of Continuing Education in the Health Professions, 25(1), 8-14.

15. Cvetkovic, A. (2009). The Integration of Immigrants in Northern Sweden: A Case Study of the Municipality of Strömsund. International migration, 47(1), 101-131.

16. Dacuycuy, L. B. (2008). The Migration of Health Professionals. Bankok: ILO Asian Regional Programme on Governance of Labour Migration.

17. Davidhizar, R. \& Dowd, S. (1999). Managing diversity in the health care workplace. [Article]. Health Care Supervisor, 17(3), 51-62.

18. Demerouti, E., Bakker, A. B., Nachreiner, F., \& Schaufeli, W. B. (2001). The job demands-resources model of burnout. Journal of Applied Psychology, 86(3), 499-512.

19. Docquiera, F. \& Rapoportb, H. (2006). The Brain Drain.

20. Dodani, S. \& LaPorte, R. E. (2005). Brain drain from developing countries: how can brain drain be converted into wisdom gain? JRSM, 98(11), 487-491.

21. Doescher, M. P., Saver, B. G., Franks, P., \& Fiscella, K. (2000). Racial and ethnic disparities in perceptions of physician style and trust. Archives of Family Medicine, 9(10), 1156-1163.

22. Eyal, N. \& Hurst, S. A. (2008). Physician Brain Drain: Can Nothing Be Done? Public Health Ethics, 1(2), 180-192.

23. Gonzalez, J. A. \& DeNisi, A. S. (2009). Cross-level effects of demography and diversity climate on organizational attachment and firm effectiveness. Journal of Organizational Behavior, 30(1), 21-40.

24. Gordon, H. S., Street, R. L., Sharf, B. F., Kelly, P. A., \& Souchek, J. (2006). Racial Differences in Trust and Lung Cancer Patients' Perceptions of Physician Communication. Journal of Clinical Oncology, 24(6), 904-909.

25. Gramm, C. L. \& Schnell, J. F. (2001). Use of Flexible Staffing Arrangements in Core Production Jobs. Industrial and Labor Relations Review, 54(2), 245-258.

26. Grignon, M., Owusu, Y., \& Sweetman, A. (2013). The International Migration of Health Professionals. In A. F. Constant \& K. F. Zimmermann (Eds.), International Handbook on the economics of migration (Vol. 1, pp. 75-97). Cheltenham, Northhampton: Edward Elgar. 
27. Gudykunst, W. B. \& Nishida, T. (2001). Anxiety, uncertainty, and perceived effectiveness of communication across relationships and cultures. International Journal of Intercultural Relations, 25(1), 55-71.

28. Hagopian, A., Ofosu, A., Fatusi, A., Biritwum, R., Essel, A., Gary Hart, L., et al. (2005). The flight of physicians from West Africa: Views of African physicians and implications for policy. Social Science \& Medicine, 61(8), 1750-1760.

29. Hentschel, T., Shemla, M., Wegge, J., \& Kearney, E. (2013). Perceived Diversity and Team Functioning: The Role of Diversity Beliefs and Affect. Small Group Research, 44(1), 33-61.

30. Hobfoll, S. E., Freedy, J., Lane, C., \& Geller, P. (1990). Conservation of Social Resources: Social Support Resource Theory. Journal of Social and Personal Relationships, 7(4), 465-478.

31. Hobman, E. V., Bordia, P., \& Gallois, C. (2004). Perceived Dissimilarity and Work Group Involvement: The Moderating Effects of Group Openness to Diversity. Group and Organization Management, 29(5), 560-587.

32. Hogg, M. A. \& Turner, J. C. (1985). Interpersonal attraction, social identification and psychological group formation. European Journal of Social Psychology, 15(1), 51-66.

33. House, J. S., Umberson, D., \& Landis, K. R. (1988). Structures and Processes of Social Support. Annual Review of Sociology, 14, 293-318.

34. Ilies, R., Johnson, M. D., Judge, T. A., \& Keeney, J. (2011). A within-individual study of interpersonal conflict as a work stressor: Dispositional and situational moderators. Journal of Organizational Behavior, 32(1), 44-64.

35. Iredale, R. (2001). The Migration of Professionals: Theories and Typologies. International migration, 39(5), 7-26.

36. Jackson, S. E., Brett, J. F., Sessa, V. I., Cooper, D. M., Julin, J. A., \& Peyronnin, K. (1991). Some differences make a difference: Individual dissimilarity and group heterogeneity as correlates of recruitment, promotions, and turnover. Journal of Applied Psychology, 76(5), 675-689.

37. Jehn, K. A., Chadwick, C., \& Thatcher, S. M. B. (1993). To agree or not agree: the effects of value congruence, individual demographic dissimilarity, and conflict on workgroup outcomes. International Journal of Conflict Management, 8(4), 287-305.

38. Jehn, K. A., Northcraft, G. B., \& Neale, M. A. (1999). Why Differences Make a Difference: A Field Study of Diversity, Conflict and Performance in Workgroups. Administrative Science Quarterly, 44(4), 741-763.

39. Karasek, R. A., Jr. (1979). Job Demands, Job Decision Latitude, and Mental Strain: Implications for Job Redesign. Administrative Science Quarterly, 24(2), 285-308.

40. King, E. B., Dawson, J. F., Kravitz, D. A., \& Gulick, L. M. V. (2012). A multilevel study of the relationships between diversity training, ethnic discrimination and satisfaction in organizations. [Article]. Journal of Organizational Behavior, 33(1), 5-20.

41. Kirby, K. \& Siplon, P. (2012). Push, Pull, and Reverse: Self-Interest, Responsibility, and the Global Health Care Worker Shortage. Health Care Analysis, 20(2), 152-176.

42. Kirchmeyer, C. (1993). Multicultural Task Groups: An Account of the Low Contribution Level of Minorities. Small Group Research, 24(1), 127-148.

43. Krajewski-Siuda, K., Szromek, A., Romaniuk, P., Gericke, C. A., Szpak, A., \& Kaczmarek, K. (2012). Emigration preferences and plans among medical students in Poland. Human Resources for Health, 10(1), 1-6.

44. LaRocco, J. M., House, J. S., \& French, J. R. P., Jr. (1980). Social Support, Occupational Stress, and Health. Journal of Health and Social Behavior, 21(3), 202-218.

45. Leavy, R. L. (1983). Social support and psychological disorder: A review. Journal of Community Psychology, 11(1), 3-21.

46. Lim, V. K. G. (1996). Job Insecurity and Its Outcomes: Moderating Effects of Work-Based and NonworkBased Social Support. Human Relations, 49(2), 171-194.

47. Lincoln, J. R., \& Jon, M. (1979). Work and Friendship Ties in Organizations: A Comparative Analysis of Relation Networks. Administrative Science Quarterly, 24(2), 181-199.

48. McKay, P. F., Avery, D. R., Tonidandel, S., Morris, M. A., Hernandez, M., \& Hebl, M. R. (2007). Racial differences in employee retention: are diversity climate perceptions the key? Personnel Psychology, 60(1), $35-62$. 
49. Milliken, F. J. \& Martins, L. L. (1996). Searching for Common Threads: Understanding the Multiple Effects of Diversity in Organizational Groups. The Academy of Management Review, 21(2), 402-433.

50. Mor Barak, M. E., Nissly, J. A., \& Levin, A. (2001). Antecedents to Retention and Turnover among Child Welfare, Social Work, and Other Human Service Employees: What Can We Learn from Past Research? A Review and Metanalysis. Social Service Review, 75(4), 625-661.

51. Mowday, R. T., Steers, R. M., \& Porter, L. W. (1979). The measurement of organizational commitment. Journal of Vocational Behavior, 14(2), 224-247.

52. Mullan, F. (2006). Doctors for the world: Indian physician emigration. Health Affairs, 25(2), 380-393.

53. Nair, M. \& Webster, P. (2012). Health Professionals' Migration in Emerging Market Economies: Patterns, Causes and Possible Solutions. Journal of Public Health, 35(1), 157-163.

54. O'Reilly III, C. A., Caldwell, D. F., \& Barnett, W. P. (1989). Work Group Demography, Social Integration, and Turnover. Administrative Science Quarterly, 34(1), 21-37.

55. Pelled, L. H., Eisenhardt, K. M., \& Xin, K. R. (1999). Exploring the Black Box: An Analysis of Work Group Diversity, Conflict and Performance. Administrative Science Quarterly, 44(1), 1-28.

56. Perrow, C. (1967). A Framework for the Comparative Analysis of Organizations. American Sociological Review, 32(2), 194-208.

57. Portes, A. \& Böröcz, J. (1989). Contemporary Immigration: Theoretical Perspectives on Its Determinants and Modes of Incorporation. International Migration Review, 23(3), 606-630.

58. Pugh, D. S. (1973). The measurement of organization structures: does context determine form? Organizational Dynamics, 1(4), 19-34.

59. Richard, O. C. (2000). Racial Diversity, Business Strategy, and Firm Performance: A Resource-Based View. The Academy of Management Journal, 43(2), 164-177.

60. Schaufeli, W. B. \& Bakker, A. B. (2004). Job demands, job resources, and their relationship with burnout and engagement: a multi-sample study. Journal of Organizational Behavior, 25(3), 293-315.

61. Shaw, J. B. \& Barrett-Power, E. (1998). The Effects of Diversity on Small Work Group Processes and Performance. Human Relations, 51(10), 1307-1325.

62. Shenkar, O. (2001). Cultural Distance Revisited: Towards a More Rigorous Conceptualization and Measurement of Cultural Differences. Journal of International Business Studies, 32(3), 519-535.

63. Sherr, K., Mussa, A., Chilundo, B., Gimbel, S., Pfeiffer, J., Hagopian, A., et al. (2012). Brain Drain and Health Workforce Distortions in Mozambique. PloS one, 7(4), 1-7.

64. Suanet, I. \& Van de Vijver, F. J. R. (2009). Perceived cultural distance and acculturation among exchange students in Russia. Journal of Community \& Applied Social Psychology, 19(3), 182-197.

65. Syed, N. A., Khimani, F., Andrades, M., Ali, S. K., \& Paul, R. (2008). Reasons for migration among medical students from Karachi. Medical Education, 42(1), 61-68.

66. Tajfel, H. \& Turner, J. C. (1986). The Social Identity Theory of Intergroup Behavior. In S. Worchel \& W. G. Austin (Eds.), Psychology of Intergroup Relations (2nd ed., pp. 7-24). Chicago: Nelson-Hall Publishers.

67. Thompson, J. D. (1967). Organizations in Action: Social Science Bases of Administrative Theory. New York,: McGraw-Hill.

68. Thompson, J. D. \& Bates, F. L. (1957). Technology, Organization, and Administration. Administrative Science Quarterly, 2(3), 325-343.

69. Tsui, A. S. \& O'Reilly III, C. A. (1989). Beyond Simple Demographic Effects: The Importance of Relational Demography in Superior-Subordinate Dyads. The Academy of Management Journal, 32(2), 402423.

70. Van De Ven, A. H., Delbecq, A. L., \& Koenig, R., Jr. (1976). Determinants of Coordination Modes within Organizations. American Sociological Review, 41(2), 322-338.

71. van Vegchel, N., de Jonge, J., \& Landsbergis, P. A. (2005). Occupational stress in (inter)action: the interplay between job demands and job resources. Journal of Organizational Behavior, 26(5), 535-560.

72. Van Yperen, N. W. \& Hagedoorn, M. (2003). Do High Job Demands Increase Intrinsic Motivation or Fatigue or Both? The Role of Job Control and Job Social Support. Academy of Management Journal, 46(3), 339-348.

73. Weech-Maldonado, R., Al-Amin, M., Nishimi, R. Y., \& Salam, F. (2011). Enhancing the cultural competency of health care organizations. Organization development in health care: Conversations on research and strategies (advances in health care management), 10. 
74. Williams, K. Y. \& O'Reilly, C. A. (1998). Demography and diversity in organizations: A review of 40 years of research. Research in Organizational Behavior, 20, 77-140.

75. Wilson, E., Chen, A. H., Grumbach, K., Wang, F., \& Fernandez, A. (2005). Effects of Limited English Proficiency and Physician Language on Health Care Comprehension. Journal of General Internal Medicine, 20(9), 800-806.

76. Zhou, W. \& Shi, X. (2011). Special Review Article: Culture in groups and teams: A review of three decades of research. International Journal of Cross Cultural Management, 11(1), 5-34. 


\section{NOTES}

